\title{
$=\mathrm{T} R A M A=$
}

\section{INSCRIÇÕES DO CORPO FEMININO EM CONTOS DE MARINA COLASANTI}

\author{
VICTÓRIA LOPES PACHECO (UFG) ${ }^{1}$ \\ FLÁVIO PEREIRA CAMARGO (UFG)²
}

\begin{abstract}
RESUMO: Este trabalho tenciona investigar como ocorre a representação das personagens femininas em três contos selecionados do livro O leopardo é um animal delicado (1998), da escritora Marina Colasanti. Para alcançar o objetivo proposto, fez-se um estudo de cunho bibliográfico, cuja análise tem como foco as protagonistas femininas dos contos "Menina de vermelho a caminho da lua", "O leopardo é um animal delicado" e "Amor e morte na página dezessete", levando em consideração o fato de terem sido criadas por uma escritora mulher - ou mulher escritora. Desse modo, a leitura de tais textos, pretendendo analisar os pontos que dizem respeito à inscrição do corpo feminino, guia-se pelo dualismo natureza/cultura e por estudos teórico-críticos que investigam questões relacionadas a gênero. Para tanto, partiremos, principalmente, dos pressupostos teóricocríticos de Elaine Showalter (1978), Lúcia Osana Zolin (2010), Rita Terezinha Schmidt (2016) e Peggy Sharpe (1997).
\end{abstract}

PALAVRAS-CHAVE: Literatura de autoria feminina. Marina Colasanti. Corpo feminino. Sexualidade.

ABSTRACT: This article intends to investigate how the representation of the female characters takes place in three short stories from O leopardo é um animal delicado (1998), by the writer Marina Colasanti. To attain the proposed objective, we have done a bibliographic research, whose analysis focuses on the female protagonists of the short stories "Menina de vermelho a caminho da lua", "O leopardo é um animal delicado" and "Amor e morte na página dezessete", assuming that they were created by a woman writer - or a writing woman. Thereby, the reading of those texts, seeking to analyze the matters that concerns the inscriptions of the female body, is guided by the nature/culture dualism and theorical-critical studies that look into questions related to gender. For this purpose, we have hold on the theorical-critical assumptions of Elaine Showalter (1978), Lúcia Osana Zolin (2010), Rita Terezinha Schmidt (2016) and Peggy Sharpe (1997).

KEYWORDS: Women's writing, Marina Colasanti, Female body, Sexuality.

\section{INTRODUÇÃO}

A premiada escritora Marina Colasanti, artista plástica por formação, nasceu em 1937 na cidade de Eritreia, mudando-se em seguida para a Itália. Mais tarde, em 1948, veio para o Brasil e aqui se mantém desde então. Ela atuou na televisão, na publicidade e na tradução de obras literárias, como As aventuras de Pinóquio, de Carlo Collodi. A autora teve sua carreira iniciada ao trabalhar como jornalista no Jornal do Brasil. Foi também colunista e redatora na revista Nova. Nesta última, mediante crônicas e ensaios pessoais, ela escrevia e se comunicava com as mulheres. Para Peggy Sharpe (1997), já nesse contexto, a autora mostrava preocupação com a representação das mulheres nos meios de comunicação e com as relações socioculturais entre os gêneros.

\footnotetext{
${ }^{1}$ Mestranda em Letras e Linguística (área de Estudos Literários) no Programa de Pós-Graduação em Letras e Linguística da Universidade Federal de Goiás (UFG), bolsista CAPES, e-mail: lopesvique@gmail.com

${ }^{2}$ Professor adjunto de Literatura Brasileira da Faculdade de Letras, da Universidade Federal de Goiás (UFG), com atuação na Graduação e no Programa de Pós-Graduação em Letras e Linguística. Líder do Grupo de Pesquisa Estudos sobre a narrativa brasileira contemporânea (CNPq/UFG) e membro do GT Homocultura e Linguagens, vinculado à ANPOLL, e-mail: camargolitera@gmail.com
} 


\title{
$=$ TRAMA $=$
}

Além disso, as questões que envolvem o feminino estão muito presentes nos livros literários de Colasanti, desde os infantis e juvenis, até os que se destinam aos adultos. Por isso, é por meio de sua obra O leopardo é um animal delicado (1998) que esta pesquisa se propõe a investigar de que maneiras a mulher é construída e, portanto, representada ficcionalmente, com foco em como o corpo feminino se insere no contexto particular de cada conto.

Para alcançar os objetivos propostos, fez-se um estudo de cunho bibliográfico, cuja análise tem como foco as protagonistas femininas dos contos "Menina de vermelho a caminho da lua", "O leopardo é um animal delicado" e "Amor e morte na página dezessete", levando em consideração o fato de terem sido criadas por uma escritora mulher - ou mulher escritora. Desse modo, a leitura de tais textos, pretendendo analisar os pontos que dizem respeito à inscrição do corpo feminino, guia-se pelo dualismo natureza/cultura e por estudos teóricocríticos que investigam questões relacionadas a gênero e aos papéis sociais, culturalmente estabelecidos, atribuídos aos corpos das mulheres.

\section{“ENTRE RESISTIR E IDENTIFICAR-SE”: A ESCRITA FEMININA EM CENA}

Marina Colasanti publicou o texto "Por que nos perguntam se existimos" no livro Entre resistir e identificar-se: para uma teoria da prática da narrativa brasileira feminina, organizado por Peggy Sharpe (1997). No referido capítulo, a escritora assegura e defende a existência de uma escrita feminina, apontando, para isso, distinções culturais, históricas e biológicas entre homens e mulheres que caracterizam suas respectivas percepções e produções literárias. Além disso, ela revela que, mesmo metamorfoseando-se, ao exercer seu ofício, em animal, pedra ou homem, é mantida sua "essência de mulher" (COLASANTI, 1997, p. 42) no processo de criação ficcional.

Esse posicionamento crítico de Colasanti se comprova no conto metaficcional "Menina de vermelho a caminho da lua". O que se passa na narrativa é a necessidade de contratação de um narrador para que a história seja contada. Assim, são trazidas algumas características esperadas e, entre elas, há uma diferenciação entre a escrita feminina e a masculina - e até mesmo uma preferência pela feminina, possivelmente por se tratar de uma narradora que representa uma personagem feminina:

\begin{abstract}
Só um apresentou-se. Teria preferido, me caberia melhor, fosse mulher. Mas não tive escolha, fiquei com ele. Homem e um pouco inexperiente, me vi obrigada a insistir na minha vontade, concisão de estilo e docilidade nos rumos. E a vesti-lo com nova roupagem. É assim, pois, de saia rosa e lenço nos cabelos, que o apresento: mãe de duas filhas pequenas que pouco irão agir, levando-as para brincar num parquinho de diversões, sábado à tarde, naquela exata tarde, naquele exato momento em que a história quer acontecer, e onde ele se torna, por contrato e escolha, seu responsável (COLASANTI, 1998, p. 16)
\end{abstract}

Colasanti (1997) ressalta que muitas escritoras afirmam a feminilidade de suas criações, especialmente em países em que o feminismo e a crítica literária feminista ocuparam espaços mais significativos. Esta última, segundo Lúcia Osana Zolin (2010), surge com a intenção de questionar como a mulher vinha sendo representada no cânone literário, majoritariamente masculino. Zolin afirma que, mesmo no Brasil, esses estudos têm sido relevantes para desestabilizar a imagem feminina estereotipada, binária e até maniqueísta de personagens que são ora angelicais, ora sensuais e pecadoras.

O cânone literário, em se tratando do Ocidente, contempla em sua maioria "obras escritas por autores brancos, masculinos e que pertencem às nações hegemônicas" (BONNICl, 2007, p. 38). Além disso, como ressalta Thomas Bonnici (2007), estudos recentes têm apontado que o cânone, dentre outros fatores, liga-se a questões como gênero e diferença 


\section{$=$ TRAMA $=$}

sexual. O autor salienta que, ao invés de ser formado de modo objetivo e impessoal - conforme determinados critérios estéticos -, esse se limita a certas barreiras sociais, institucionais e políticas.

Para Elaine Showalter (1978, apud BONNICl, 2007, p. 38), toda uma tradição foi negligenciada por críticos homens. Portanto, em uma sociedade patriarcal, que acaba por interferir no estabelecimento do cânone, deixou-se por muito tempo à margem a produção literária feminina. Para Elodia Xavier (1999, p. 18, apud BONNICI, 2007, p. 39), "a crítica oficial, com raras exceções, atribuía um estatuto inferior à mulher escritora e cobrava delas formas consideradas mais adequadas à 'sensibilidade feminina'”.

Assim, conforme o feminismo foi abrindo as portas para a voz feminina, a literatura feita por mulheres, construída de outra perspectiva, parece vir com a missão de modificar o modo como vinham acontecendo as representações das personagens femininas na literatura. Neste sentido, o que se percebe no que foi pesquisado pela crítica feminista no Brasil a partir dos anos 1980 é que houve uma "re-escritura de trajetórias, imagens e desejos femininos" (ZOLIN, 2010, p. 186).

Regina Dalcastagnè (2007), em seu estudo "Imagens da mulher na narrativa brasileira", assim como Zolin, aponta algumas diferenças entre como ocorre a representação feminina em obras escritas por homens e por mulheres, pensando no contexto do romance brasileiro contemporâneo. A distinção é também evidenciada em números: a pesquisa, cujo recorte analisa os textos publicados por três grandes editoras durante os 15 anos anteriores à sua execução, mostra que as autoras não correspondem nem a $30 \%$ dos escritores desses livros. Esse dado, para a estudiosa, interfere na porcentagem de personagens mulheres nas narrativas cujas autorias são masculinas (32,1\%) e femininas (52\%).

Nesse sentido, levando em consideração que, como disse Schmidt (2016), nenhuma convenção é arbitrária e que os valores sociais e literários se convergem, faz-se importante pensar no modo como as representações do ser feminino vêm acontecendo, de modo a refletir como elas estão ligadas à subjetividade da autora que aqui está em questão, a qual, para Alexandra Almeida de Oliveira e Vanessa Gomes Franca (2009), demonstra ter uma postura feminista.

Conforme Schmidt (2016, p. 357), "a literatura, desde a antiguidade, constitui um repositório imagético de construções culturais do corpo humano". A estudiosa cita ainda Simone de Beauvoir (2009) quando fala sobre "o quanto o corpo das mulheres inscreve sentidos culturais pressupostos em certas noções de feminilidade que, reforçadas socialmente, são introjetadas por elas a ponto de determinar a percepção de si próprias" (SCHMIDT, 2016, p. 357). Neste sentido, é partindo desse princípio de Schmidt que se pretende fazer uma leitura dos contos selecionados de modo a verificar como esses corpos femininos estão inseridos ficcionalmente na obra de Colasanti.

No conto "Menina de vermelho a caminho da lua" a narração começa com a detentora da história a ser contada, uma história da qual não consegue se livrar. Ela a descreve como um "mênstruo", valorando logo de início um fluído natural do corpo feminino como algo repugnante e desnecessário, como a história a ser contada. Essa visão depreciativa da menstruação vem desde Aristóteles. Segundo Schmidt (2016), ele foi um dos primeiros pensadores a partirem da diferença sexual para entender a natureza humana, de modo que o filósofo via as mulheres como inferiores, o que se devia a

[...] um defeito constitutivo que é seu corpo frio, incapaz, portanto, de transformar o sangue menstrual em sêmen, substância que carrega a latência do ser humano completo. Segundo seus argumentos, o homem doa a substância do ser (a alma, 


\title{
$=$ TRAMA $=$
}

a forma) na cópula, enquanto a mulher, embora não destituída de elementos da alma, supre o ser de forma passiva, apenas com a matéria, inferior à forma. Isso significa dizer que a latência da substância não se concretiza na concepção do ser feminino, um ser incompleto por natureza (SCHMIDT, 2016, p. 344).

Portanto, não querendo se responsabilizar pela história, a mulher que a detém coloca no jornal um anúncio para a contratação de um narrador, como fora dito anteriormente. Nesse sentido, é possível também refletir que a necessidade de outra pessoa para narrar corresponda ao fato de que, como destacou Xavier (1999 apud BONNICI, 2007, p. 39), muitas escritoras optavam pelo uso de pseudônimos ou mesmo pelo anonimato para evitar a rejeição ou mesmo o escândalo. A dona da história, com efeito, sente que precisa contá-la conforme seus requisitos, tanto que irá guiar, criticar e impor suas vontades à medida que o narrador contratado exerce seu trabalho, mas reforça que não a pretende assumir. Faz até, mais adiante no conto, repreendendo o narrador, a seguinte ressalva: "quisesse assim tão delicada, eu mesma escrevia" (COLASANTI, 1998, p. 22).

Para começar a escrever, o narrador é como que travestido de "saia rosa e lenço nos cabelos" (COLASANTI, 1998, p. 16), incorporando a narradora personagem que irá vivenciar o enredo. Trata-se de uma mãe que leva as filhas a um parque de diversões cheio de precariedades. Lá, as meninas se interessam por um brinquedo que simula a lua e, enquanto espera as filhas terminarem de brincar, a mulher depara-se com uma garota.

Chama sua atenção que essa criança, toda vestida de vermelho, quer experimentar o mesmo brinquedo em que estão suas filhas, mas parece não ter dinheiro para pagar por um bilhete. Assim sendo, todo o conto gira em torno dessa mãe que observa a menina de vermelho, atribuindo muitos significados às ações desta última. Partindo desse olhar da mãe, guiado pela dona da história, é possível pensar sobre como a representação do feminino ocorre no contexto do conto. A narradora a descreve da seguinte forma:

\begin{abstract}
Já estava no parque quando cheguei, figurinha vermelha brincando com outras crianças nas canoas volantes. Dez anos talvez, de longe mais. O carmim do batom pesa nos lábios, mas os seios ainda não são seios, e a cintura no alto espera crescimento. Por que tem uma máscara vermelha levantada sobre a testa, se o carnaval já passou? A tela encerada, recortada em folhas, esmaga mechas úmidas, e como uma borboleta pousada ao acaso, se contrapõe ao rasgado dos olhos. Não parece sentir frio, exposta na malha curta. Olha levantada sobre a ponta dos pés, o corpo todo encostado à superfície curva, as coxas nuas coladas contra a bolha, enquanto a boca se abre amolecida de vontade (COLASANTI, 1998, p. 19-20).
\end{abstract}

Muitos pontos desse excerto são dignos de destaque. Nota-se claramente que a descrição é carregada de extrema sensualidade. Tal característica irá se repetir inclusive na interação da menina com o brinquedo, quando é dito, por exemplo, que "'A mão se enfia por baixo da língua de plástico [...]'” (COLASANTI, 1998, p. 21). Portanto, com uma leitura atenta, fica claro que toda a malícia é atribuída pela narradora - seguindo as devidas ordens - e que ela se realiza na figura da garota de dez anos.

Analisando apenas o que a menina faz em todo o conto, na tentativa de levar o menos possível em consideração a perspectiva valorativa da mãe que narra, chega-se à conclusão de que a "figurinha vermelha" não age de maneira muito diferente de qualquer outra criança de sua idade. Aparentemente, o que está sendo contado nessa "pequena história sem fatos" diz respeito à leitura que a mulher fez de uma situação corriqueira, em que nada efetivamente acontece. Pode-se pensar, por isso, que tudo que ela vê ali é o que ela quer ver, e não o que realmente é. Há inclusive momentos em que parece gostar muito do que observa, tanto que 


\section{$=$ TRAMA $=$}

não interrompe o que acha que está a se desenrolar, como quando a dona da história sugere que a narradora "está úmida, seivando secreta ao sol do parque, presa com o homem na teia viscosa" (COLASANTI, 1998, p. 23).

Também é impossível ignorar toda a cor vermelha ligada à imagem da garota. O uso dessa coloração não pode ser compreendido como um dado imprevisto. O rubor contribui para a construção do retrato que se faz dessa menina-mulher, a qual, para a mãe, usa seu corpo e sua sensualidade para conseguir o que quer. Em um estudo muito significativo que investiga este conto, Ludmila Santos Andrade afirma:

O pensamento misógino tem a característica de responsabilizar e culpar a mulher desde a história edênica pelo pecado da sedução. No conto, o mesmo acontece quando o velho é inocentado da ação, pois fica explícito que "a menina está seduzindo o velho", e não o contrário. A utilização da cor vermelha corrobora e completa a cena do quadro da menina que se apresenta como mulher sedutora reverberando o pensamento misógino de Tertuliano. Ele considerava que as mulheres já nasciam em condições pecaminosas para a concupiscência da carne e essa condição ganhava ênfase especial naquelas mulheres que manchavam as faces de carmim revelando o desejo pelo pecado, pois o vermelho lembra a sedução, o sangue e a concupiscência da carne (ANDRADE, 2015, p. 107).

O dualismo natureza e cultura, segundo Schmidt (2016), é o mais persistente da filosofia ocidental e sustenta "distinções universalizantes entre concepções de humano e de não humano, e entre seres homem e mulher" (SCHMIDT, 2016, p. 344). Nesse binarismo, a mulher estaria ligada à natureza. Ainda para a pesquisadora, antes do período moderno, as mulheres eram associadas ou a uma figura benevolente e maternal, ou a um ser indomável com poderes destrutivos - poderes esses que deveriam ser controlados. Posteriormente, já na modernidade vinculada ao sistema capitalista, surge "a demanda por uma ética sexual pautada na necessidade de domesticar as mulheres" (SCHMIDT, 2016, p. 349). Toda essa descrição de "feminino selvagem" parece se relacionar com o modo como a menina de vermelho é vista.

Nota-se que esse aspecto se reforça quando são percebidas as associações estabelecidas pela narradora entre a criança e alguns bichos, como, por exemplo, quando a retrata como um "cavalinho gracioso", cujo corpo "relincha, se empina, se estica" (COLASANTI, 1998, p. 20-21), ou como uma aranha que tece "ao redor do homem a seda que prenderá seu olhar" (COLASANTI, 1998, p. 21-22), e também como "quati de dentinhos cariados" (COLASANTI, 1998, p. 22). Essa clara animalização a aproxima da dita selvageria e a afasta da condição de ser humano. Sobre esse processo desumanizador das mulheres, Schmidt (2016) reitera que, no dualismo natureza/cultura, o ser mulher veio a se inserir em uma categoria intermediária entre o humano e o não humano. Para a autora,

Não resta dúvida de que tanto o racionalismo filosófico quanto o empiricismo científico, consagram, a seu modo, os dualismos cultura/natureza, mente/corpo e sujeito/objeto como absolutos hierárquicos, pautados pelo ideal de uma mente que, supostamente, transcende toda a diferença sexual, mas que se inscreve, no conjunto dos discursos, claramente como masculina, pois é em relação a ela que o feminino emerge como lugar da diferença, codificada pela materialidade do corpo, não raro inserido no contexto da discussão em torno dos animais, os quais são, via de regra, reduzidos à condição de máquinas reprodutoras (SCHMIDT, 2016, p. 346).

Portanto, fica evidente a sexualidade atribuída à garota. E, tendo sido essa caracterização realizada na perspectiva da narradora mãe, muito se percebe da representação que ocorre não só em relação à própria menina, como também dessa mulher que concede sentido àquilo que observa. 


\section{$=$ TRAMA $=$}

A respeito da menina, como já foi dito, o conto nos revela que, mesmo se tratando de uma criança, a malícia de se conseguir o que quer utilizando-se do próprio corpo não é simplesmente atribuída a ela: a garota é culpabilizada por seduzir um velho para experimentar o brinquedo. Mesmo que algo estivesse de fato acontecendo, o que não parece ser o caso, a responsabilidade, na visão do narrador - que se materializa na narradora personagem -, seria da garota, e não do homem possivelmente interessado em tirar proveito disso. Pode-se também entender que essa imagem construída da menina se deve à precoce adultização que recorrentemente é feita em relação às crianças do sexo feminino, como ocorre no conto de Colasanti, pois mesmo os seios que "ainda não são seios" são erotizados.

Mas, além disso, há também uma informação significativa quanto a essa mulher que narra. Nota-se como muitas vezes se porta uma mulher diante de outra. Essa mãe - cuja maternidade não se estende a como se sente em relação à criança de vermelho -, ilustra as ideias defendidas por Beauvoir (2009 apud SCHMIDT, 2016): as concepções de feminilidade, inscritas cultural e socialmente, acabam por interferir na maneira como as mulheres se enxergam. Em vista disso, o modo como essa mulher - ou essas mulheres, levando em conta a dona da história e a narradora incorporada pelo narrador contratado por ela - vê a menina de vermelho diz muito mais sobre ela própria e como essa personagem que narra deve se entender como ser feminino, do que a respeito da menina de vermelho.

\section{CORPO, EROTISMO E SEXUALIDADE FEMININA EM "O LEOPARDO É UM ANIMAL DELICADO" E "AMOR E MORTE DA PÁGINA DEZESSETE”}

O conto "O leopardo é um animal delicado", homônimo ao título do livro, apresenta muitas semelhanças em relação ao "Menina de vermelho a caminho da lua", como será possível perceber mais adiante. Porém, algumas diferenças são de grande relevância.

Em "O leopardo é um animal delicado", ao contrário do que acontecia no texto anterior - que possuía caráter metaficcional e narradora personagem -, o narrador neste conto é em terceira pessoa, além de haver referências eróticas na narrativa não somente por insinuações ou por uma interpretação discursiva, mas por meio de uma construção gradual de momentos eróticos entre os personagens envolvidos.

"O leopardo é um animal delicado" começa com a protagonista lavando a louça, quando percebe que algo - não se sabe ainda ao certo se um circo, ou um parque de diversões - chega à cidade, e ela prontamente, sem saber do que se tratava, decide que comparecerá. Ela logo pensa na roupa que usaria no dia: "o vestido vermelho de bolinhas, porque tinha um jeito de seda e uma saia godê que the acariciaria as coxas quando andasse sobre os saltos altos" (COLASANTI, 1998, p. 82).

Nota-se que o processo de erotização se inicia já no princípio do conto, aliado novamente à simbologia da cor rubra, que a protagonista também usa nas unhas, pintando-as antes de sair de casa. Mesmo nos momentos que antecedem a feira, que ela descobre se chamar "Erotika Tour", a protagonista já esperava, de sua residência, ouvir alguma música que a fizesse "mover o corpo dançante", mas, para seu desapontamento, a música que de lá tocava não era "nada erótica" (COLASANTI, 1998, p. 83). A personagem se arrepia só de imaginar o que aconteceria no evento. Fica claro, assim, que há uma expectativa. O desejo, que norteará essa mulher por todo o texto, já está instaurado desde o início da narrativa.

A partir do momento em que a personagem cruza o letreiro da feira, ela passa por diversas barraquinhas. Há um momento em que ela sente fome e chama a atenção o fato de que a cor, o aroma e a quentura da comida afrodisíaca abrasam-Ihe o corpo. Em seguida, ela observa as atrações, entra em uma fila, mas logo a deixa e decide beber algo. Mais uma vez o 


\title{
$=$ TRAMA $=$
}

desejo da mulher é destacado e, neste momento, degustando o "Hidromel", a erotização já se mostra de maneira mais explícita:

\begin{abstract}
Sentiu os lábios pegajosos, lambeu com vagar aquele gosto de mel, lambeu demorando-se nos cantos, depois levou à boca os dedos com que havia segurado o copo, meteu dois entre os lábios, lambeu-os devagar, contornando cada dedo com a língua sem saber ao certo se o gosto de mel era deles ou da boca mas lambendo, lambendo assim mesmo. Tirou os dedos da boca lentamente e molhados e doces os deixou deslizar sobre os lábios (COLASANTI, 1998, p. 86).
\end{abstract}

Observa-se aqui uma conotação sexual bem acentuada nos gestos da mulher. Como no conto anterior, é perceptível que, de maneira ainda mais intensa, em "O leopardo é um animal delicado" a animalização feminina associada ao erotismo dos corpos se torna mais explícita. Como ressaltam Oliveira e Franca (2009, p. 24), "os vocábulos lambeu, boca, dedos, meteu e outros não deixam dúvidas sobre o desejo sexual da personagem, que aqui é descrita como se fosse um animal que lambe". Esse momento em que ela está na barraca de bebidas parece corresponder aos instantes que precedem a caçada, em vista do que se desenrolará em seguida.

Um "sinal de alerta" é disparado, o que a atrai para o "Túnel do Amor". Nesse lugar, como em uma floresta com sons "sussurrantes, de água, ou vento", era preciso "acostumar o olhar" (COLASANTI, 1998, p. 86). Ela mantinha "as mãos tensas, prontas a agarrar ou defender" (COLASANTI, 1998, p. 87), quando surgiu um homem de cabelos compridos. Ela o toca e sente que sua roupa remete a "couro de fera, leopardo". A mão dele, que a tinha tomado pela cintura, desce para os quadris. A cintura, segundo Pierre Bourdieu (2007, p. 25), é um "símbolo de clausura" e também "limite simbólico" - limite esse que, nessa ocasião, é ultrapassado. Para ele, essa parte do corpo da mulher "simboliza a barreira sagrada que protege a vagina, socialmente constituída em objeto sagrado" (BOURDIEU, 2007, p. 25). No caso, a protagonista do conto não parece interessada em estabelecer qualquer barreira que seja.

Mesmo o primeiro e o segundo homem sendo descritos como leopardos - este último, inclusive, como "leopardo sem fúria" -, a selvageria parece vir não deles, mas da própria protagonista. Ela gostaria, aliás, que eles fossem adiante: "mão que ela queria sentir deslizar para o lado de dentro da coxa, para o lado secreto, e que ao contrário se retirava" (COLASANTI, 1998, p. 88). E, quando entra o terceiro homem, a mulher, cheia de desejo, parece escolher a presa: "Este! exigiu de repente seu corpo exasperado. Este, agora!" (COLASANTI, 1998, p. 88).

É exatamente a partir desse instante que ela impõe seu poder e passa a dominar toda a situação. A personagem rasga "o decote com os dentes e as unhas, de um tranco" (COLASANTI, 1998, p. 88). Mesmo ele se esquivando, ela procura a boca do rapaz, sente a sunga, crava as unhas em sua nádega e os dentes no pescoço, abocanhando o homem como um bicho. Por fim, ela o derruba: "Ela caiu por cima dele, mordeu-lhe a boca, mordeu-lhe a língua, enfiou a mão na sunga. E o cavalgou, o cavalgou desatinada". A esse respeito, Bourdieu (2007) diria que houve uma inversão da posição considerada normal do ato sexual. Segundo o autor:

[...] em cima ou embaixo, ativo ou passivo, essas alternativas paralelas descrevem o ato sexual como uma relação de dominação. De modo geral, possuir sexualmente, como em francês baiser ou em inglês to fuck, é dominar no sentido de submeter a seu poder, mas significa também enganar, abusar ou, como nós dizemos, "possuir" (ao passo que resistir à sedução é não se deixar enganar, não se deixar "possuiu) (BOURDIEU, 2007, p. 29). 


\section{$=$ TRAMA $=$}

Ao final do conto, a mulher sai e sente "as unhas viscosas, olhou os dedos tingidos de vermelho" (COLASANTI, 1998, p. 89). Este é o primeiro momento, nos dois contos até então analisados, em que o vermelho refere-se diretamente a sangue, indicando, na presente circunstância, os resquícios da caçada. O leopardo, por fim, é a própria protagonista - um leopardo, sem nenhuma delicadeza, que representa metaforicamente uma mulher ativa, dominadora, que caça a sua presa.

Portanto, neste conto, assim como em "Menina de vermelho a caminho da lua", a animalização e a erotização da mulher andam juntas, de maneiras distintas em cada um dos contos. Sobre "O leopardo é um animal delicado", Vera Maria Tietzmann Silva (2015, p. 183) afirma que "causa perplexidade no leitor, mais do que as ações mesmas, a constatação de como é tênue e impreciso o limite que separa a razão do puro instinto, a natureza humana da natureza animal do homem" - que, de acordo com esta análise, seria, na verdade, uma natureza animal específica da mulher que, para Schmidt (2016), distancia o ser feminino da condição humana, como já apontado anteriormente.

No que diz respeito à dominação durante a relação sexual, Bourdieu (2007) aponta para uma assimetria em relação à representação dos dois sexos. Para ele, as mulheres "estão socialmente preparadas para viver a sexualidade como uma experiência íntima e fortemente carregada de afetividade, que não inclui necessariamente a penetração" (BOURDIEU, 2007, p. 30), enquanto que os homens "tendem a 'compartimentar' a sexualidade, concebida como um ato agressivo, e sobretudo físico, de conquista orientada para a penetração e o orgasmo" (BOURDIEU, 2007, p. 30). Consequentemente, o homem ocuparia o papel de ativo e à mulher seria atribuída a passividade.

Em se tratando do conto "O leopardo é um animal delicado", a protagonista parece se assemelhar muito mais a um estereótipo ligado ao homem do que à mulher. Entretanto, não é uma mera semelhança ao que é entendido como masculino. O que se passa na narrativa é, na verdade, a extrapolação desses padrões culturalmente estabelecidos e inscritos pelos corpos femininos e masculinos.

Assim sendo, a mulher representada em "O leopardo é um animal delicado" transgride e transcende - através das experiências vividas por esse corpo feminino - "um modelo idealizado e consagrado por poderes seculares e religiosos e instrumental na codificação de práticas sociais" (SCHMIDT, 2016, p. 350), evidenciando que a mulher sente desejo sexual até mesmo quando desassociado da afetividade - e é capaz de realizá-lo de modo ativo e não apenas passivamente.

Já o conto "Amor e morte na página dezessete" traz a problemática da mulher inserida em um casamento, mas que, apesar de estar com seu marido há 27 anos, tem um amante há 25. Ao contrário da maior parte das personagens do livro - que não são nomeadas -, a protagonista se chama Selena, enquanto que o marido e o amante recebem os nomes Jonas e Daniel, respectivamente. Segundo Vera Maria Tietzmann Silva (2007, apud OLIVEIRA e FRANCA, 2009, p. 21), os nomes não foram escolhidos aleatoriamente. Na verdade, para ela, sugerem o perfil das personagens: Selena, ligada às duas faces da lua, em que uma é visível e a outra é oculta; Jonas, estabelecendo um intertexto com o profeta bíblico que naufraga e é devorado por uma baleia e, assim, não vê o que acontece ao redor; e Daniel, o qual, diferentemente do profeta do Livro de Daniel que entra na cova dos leões e não é atacado, morre devorado pelas feras ao tentar provar seu amor por Selena.

Silva (2007, apud OLIVEIRA e FRANCA, 2009, p. 21) chama ainda a atenção para o fato de que o triângulo amoroso estabelecido foge do que seria o mais comum para o plano de realidade, por se tratar de uma mulher que se relaciona com dois homens, e não o inverso. Tal percepção se associa à noção popularmente defendida de que é o homem que tem 


\section{$=$ TRAMA $=$}

necessidades sexuais mais latentes e que, por isso, é mais comum que ele tenha amantes ou, até mesmo, se satisfaça com prostitutas - ideias que, ao contrário do que se fosse com uma mulher, não causam nenhum espanto.

As relações que a mulher cultiva com marido e amante são bastante distintas e têm funções diferentes na vida de Selena, apesar de ela dizer que ama os dois homens. Por um lado, Jonas é descrito como "um bom marido [...], ciumento, meio bruto, mas bom" (COLASANTI, 1998, p. 145). Ele parece estar ligado ao conforto do matrimônio, do lar, de ter uma casa para onde vai voltar. O homem inclusive se questiona quanto ao motivo pelo qual estaria sendo traído, já que "ele não Ihe deixava faltar nada" (COLASANTI, 1998, p. 146). Jonas, assim, parece cumprir o papel protocolar de marido provedor, com o qual Selena se acostumou a ter como companheiro.

Por outro lado, Jonas parece não atender a algumas vontades importantes da esposa, como levá-la ao circo ou, especialmente, ao seu desejo sexual. No conto, o marido percebe que "não era o macho que sempre havia esgotado as vontades da sua fêmea mas apenas um homem que gozava" (COLASANTI, 1998, p. 145). A esse respeito, Bourdieu ressalta que

O gozo masculino é, por um lado, gozo do gozo feminino, do poder de fazer gozar: assim Catherine MacKinnon sem dúvida tem razão de ver na "simulação do orgasmo" (faking orgasm) uma comprovação exemplar do poder masculino de fazer com que a interação entre os sexos se dê de acordo com a visão dos homens, que esperam do orgasmo feminino uma prova de sua virilidade e do gozo garantido por essa forma suprema da submissão (BOURDIEU, 2007. p. 30).

Portanto, Jonas percebe que não era suficiente para sua mulher em absolutamente tudo. Daniel, porém, parecia exercer essa função que faltava, tanto que no início do relacionamento os encontros aconteciam apenas no motel, tamanho o desejo que sentiam. $\mathrm{O}$ amante gostava de agradar Selena e a fazia se sentir jovem. Era como que um namoro juvenil, contrapondo a estabilidade doméstica proporcionada pelo marido.

Selena "tão assentada em querer os dois, surpreendia-se quase de que não vivessem todos juntos na mesma casa, partilhando a mesa além da cama" (COLASANTI, 1998, p. 143), o que se justifica justamente por contemplarem as necessidades da mulher de maneiras diferentes, de modo que ela apenas se sentia completa estando com ambos.

Sobre essa protagonista é relevante notar que, apesar de ser casada, nenhum filho é citado no conto. Assim, não exercendo o cargo de mãe, ela foge de um modelo do que se espera do ser feminino, constantemente ligado à função materna. Julia Kristeva (1988, apud SCHMIDT, 2016, p. 350) afirma que

[...] em muitas civilizações o feminino foi efetivamente incorporado ao materno, mas o fato do pensamento feminista na cultura ocidental ter identificado o materno como um dos principais locus de descontentamento pode ser explicado tendo em vista a construção específica do feminino sob a égide do capitalismo. Essa construção diz respeito à aporia forjada pelo sistema econômico e pelo modelo de pensamento que Ihe dá suporte: de um lado, a consagração cultural da representação do feminino associado ao materno, de outro a desvalorização política e congênita da mulher cujo corpo, objetificado pelo olhar masculino e, em muitas situações, controlado por leis ditadas pelos homens, figura a própria alienação da mulher de si mesma (SCHMIDT, 2016. p. 350).

Vê-se, por isso, que a mulher representada em "Amor e morte na página dezessete" escapa de tal estereótipo, tendo muita consciência de suas vontades e não as colocando de lado, além de seguir suas próprias regras. Selena não se deixa controlar por nenhum dos 


\section{$=$ TRAMA $=$}

homens. Um exemplo disso é que, mesmo o marido se incomodando com o vestido decotado e curto da mulher - dado por Daniel -, a personagem continua usando-o.

Esse vestido, por sua vez, é vermelho, como o esmalte usado pela protagonista no dia da morte do amante. Mais uma vez, Colasanti faz o uso dessa cor emblemática. Logo, a simbologia dessa cor é um dos pontos de contato entre as três protagonistas dos contos que foram analisados, sendo utilizada na caracterização dessas mulheres que, com seus corpos em movimento, vão além do que é culturalmente esperado de um padrão feminino considerado como "natural".

\section{CONSIDERAÇÕES FINAIS}

Marina Colasanti, no conjunto de sua obra, problematiza algumas discussões acerca da condição feminina, o que se repete em O leopardo é um animal delicado. Nos contos analisados neste estudo é possível constatar, por meio de diferentes ângulos, que os corpos femininos são colocados em posições distintas aos estereótipos que tentam determinar e limitar o que é o ser feminino.

Utilizando-se de perspectivas e estratégias variadas, a autora ressignifica uma menina de dez anos, uma mulher cheia de desejo e uma esposa. Por meio da animalização, do uso de símbolos - como a cor vermelha - e das descrições, por exemplo, é possível notar que há uma contestação da mulher que se liga à natureza, a qual se opõe ao homem ligado à cultura.

Assim, é possível pensar que Colasanti, ao invés de atribuir uma visão restritiva e maniqueísta das mulheres, insere seus corpos de maneira que supere papéis femininos preestabelecidos, contemplando a diversidade e a complexidade das mulheres, porque, apesar de se tratar da construção ficcional de um grupo, este é diverso.

Logo, conclui-se que, apesar de muitas mulheres estarem em concordância com tudo o que foi constituído como feminino até hoje, de acordo com as representações analisadas nos três contos selecionados verificou-se que o olhar a respeito da sexualidade e do corpo femininos vem superando uma imagem limitadora que costumava ser literariamente reiterada, como foi apresentado nesta pesquisa. Portanto, autoras que encabeçam uma perspectiva feminista, como o faz Marina Colasanti, abrem espaço para que os papéis das mulheres sejam repensados e, consequentemente, que a liberdade feminina - não só em relação ao sexo, mas até ao próprio trabalho e à família heteropatriarcal - se estabeleça de modo cada vez mais significativo, rompendo com estereótipos arraigados em relação ao corpo, à sexualidade e à condição feminina de mulheres que são constantemente subjugadas na e pela sociedade.

\section{REFERÊNCIAS}

ANDRADE, Ludmilla Santos. Metaficção, misoginia, linguagem feminina em "Menina de vermelho a caminho da Lua". In: BORGES, Kelio Junior Santana (Org.). Traços de Essencialidades. Goiânia: Kelps, 2015. p. 99127.

BONNICI, Thomas. Teoria e crítica literária feminista: conceitos e tendências. Maringá: Eduem, 2007. BOURDIEU, Pierre. A dominação masculina. Trad. Maria Helena Kühner. 5a. ed. Rio de Janeiro: Bertrand Brasil, 2007.

COLASANTI, Marina. O leopardo é um animal delicado. Rio de Janeiro: Rocco, 1998. . Por que nos perguntam se existimos. In: SHARPE, Peggy (Org.). Entre resistir e identificar-se: para uma teoria da prática da narrativa brasileira de autoria feminina. Florianópolis: Editora Mulheres; Goiânia: Editora da UFG, 1997. p. 33-42.

. A nova mulher. $8^{\mathrm{a}}$. ed. Rio de Janeiro: Nórdica, 1980.

Mulher daqui pra frente. $5^{a}$. ed. Rio de Janeiro: Nórdica, 1981.

COLLODI, Carlo. As aventuras de Pinóquio. Trad. Marina Colasanti. Rio de Janeiro: Companhia das Letrinhas, 2002.

DALCASTAGNĖ, Regina. Imagens da mulher na narrativa brasileira. In: O Eixo e a Roda, v. 15, p. 127-135, 2007. 
OLIVEIRA, Alexandra Almeida de; FRANCA, Vanessa Gomes. A condição feminina e os intertextos presentes em O leopardo é um animal delicado, de Marina Colasanti. In: CAMARGO, Flávio Pereira; CARDOSO, João Batista (Org.). Percursos da narrativa brasileira contemporânea: coletânea de ensaios. João Pessoa: Realize Editora, 2009. p. 11-33.

SCHMIDT, Rita Terezinha. Para além do dualismo natureza/cultura: ficções do corpo feminino. In: RODRIGUES, Carla; BORGES, Luciana; RAMOS, Tânia Regina Oliveira (Org.). Problemas de Gênero. Rio de Janeiro: Funarte, 2016. p. 343-368.

SHARPE, Peggy. Imagens e poder: construindo a obra de Marina Colasanti. In: (Org.). Entre resistir e identificar-se: para uma teoria da prática da narrativa brasileira de autoria feminina. Florianópolis: Editora Mulheres; Goiânia: Editora da UFG, 1997. p. 43-55.

SILVA, Vera Maria Tietzmann. O leopardo é um animal delicado: entre o trivial e o insólito. In: BORGES, Kelio Junior Santana (Org.). Traços de Essencialidades. Goiânia: Kelps, 2015. p. 171-192.

ZOLIN, Lúcia Osana. Questões de gênero e de representação na contemporaneidade. In: Letras (UFSM), v. 41, 2010, p. 183-196. 